\title{
The influence of emotional regulation strategies in the relationship between test anxiety and performance in the educational competitions context of adolescents with high intellectual abilities
}

\section{Roxana I. HOLIC ${ }^{\bullet}$ Carmen CREŢU}

\begin{abstract}
Competitions are one of the most important and attractive activities for students in Romanian schools because they give them the opportunity to deepen the study of a certain discipline and to achieve performance in the favorite field. What is somewhat neglected in literature about educational contests is precisely the presence and influence of emotions experienced by students in the context of competitions that may have a positive or negative impact on the performance achieved. Test anxiety is the most frequently studied phenomenon and mentioned as a problem in the educational psychology, but there are no studies (at least identified by us) that have approached this topic with direct reference to the context of educational competitions (except for sports studies that frequently addresses the issue of competitive anxiety). Another aspect that is rather little studied in research concerned with academic emotions is the influence of emotional regulation on academic performance. Very few studies address the role that emotional regulation strategies have in the relationship between test anxiety and performance.Given the lack of studies on the impact of test anxiety and emotional regulation strategies on performance in educational competitions of adolescents with high intellectual abilities, we have investigated this issue in this study. The selected group of subjects consisted of 541 teenagers who participated in various national Olympiads (2017). The results show that cognitive test anxiety has a positive influence on the performance achieved in educational competitions. Even though emotional regulation strategies do not moderate the relationship between test anxiety and performance, they still have some relationship with both. Thus, test anxiety has positive relationships with all emotional regulation strategies, less with cognitive reappraisal. Performance has only positive relationships with two of the emotional regulation strategies (task-focused strategies and emotion-focused strategies) and negative relationships with other two of them (cognitive-appraising strategies and suppression). These links identified between the variables analyzed can be a contribution to the educational practice,
\end{abstract}

\footnotetext{
- PhD Student Alexandru Ioan Cuza University, Faculty of Psychology and Education Sciences, , Iasi, România. Corresponding author. Tel.: 0747536280,roxanaholic@yahoo.com

- PhD Professor Alexandru Ioan Cuza University, Faculty of Psychology and Education Sciences, Toma Cozma Street no 3, Iași 700554, România
} 
both for students participating in various educational competitions as well as in the case of day-to-day school performance.

Keywords: test anxiety; performance; emotional regulation strategies; educational competitions; high intellectual abilities.

\section{Introduction}

Test anxiety is the most frequently cited factor that has a negative influence on academic performance. Test anxiety is a strong emotional reaction that an individual experience before and during an examination (Akca, 2011). When students are placed in an evaluative situation, comparative and competitive behaviors will lead to increased anxiety that will disrupt their focus on doing what they need to successfully complete their work tasks (Zeidner \& Matthews, 2011). Test anxiety is a serious problem for many students in secondary school, high school and higher education students (Ergene, 2003). Although large-scale studies have seen a decrease, approximately $33 \%$ of students experience test anxiety (Methia, 2004), and those with high levels do not give a very high academic performance (Bedell \& Marlowe, 1995; King, Ollendick, \& Prins, 2000). Test anxiety is studied in the context of the field dedicated to academic emotions. Pekrun and collaborators (2002a) defined academic emotions as "those emotions experienced in academic contexts and associated with learning and achievement activities". Such emotions, for example, relate to the pleasure of learning, the success offered, the anger manifested when the tasks received are too difficult or impossible to achieve, or the anxiety experienced in an assessment context. In the past, academic emotions have largely been neglected in research in the field of educational psychology, with the exception of test anxiety.

In terms of research in the academic field on emotions and emotional regulation, the subject that attracted attention was the anxiety manifested in the evaluative context (Pekrun et al., 2002a; Schutz \& Pekrun, 2007) and how students manage their anxiety during the examination process (Kondo, 1997). Conclusions of studies suggest that the regulatory function is associated with academic outcomes through behaviors and attitudes towards tasks. For example, students with a higher level of control tend to participate more actively in classes, and this has led to higher levels of academic performance (Valiente et al., 
2014). Also, students with higher levels of emotional regulation also had better skills in carrying out certain academic tasks, and a higher level of academic competence (Trentacosta \& Izard, 2007).

The objective of our study is to identify the extent to which the anxiety manifested in the context of educational competitions influences the performance of adolescents with high intellectual abilities participating in national academic competitions. We also want to investigate the relationship between emotional regulation strategies used by participants and their performance. Finally, we want to test the moderator role of emotional regulation strategies in the relation between test anxiety and performance for the educational competitions context of adolescents with high intellectual abilities.

\section{Test anxiety concept}

Sarason (1980), Spielberger and Vagg (1995) define test anxiety as the predisposition of an individual to react through a state of excessive concern, intrusive thoughts, mental disorganization, tension, and physiological activation when is exposed to an evaluation situation. Obtaining lower scores or results in tests, experimenting shame and embarrassment, and the fact that they might disappoint some important people around them are some of the consequences of the evaluation that students perceive to be threatening (Zeidner, 2007, Pekrun et al., 2011).

For those with test anxiety, both preparation for an examination and the examination itself are causing a high level of mental anxiety and discomfort (Cohen et al., 2008). As a result, affected students fail to meet their potential, and the results of their evaluation do not represent them or their real level of knowledge and learning (Shobe, Brewin, \& Carmack, 2005).

At the beginning of the research on the "test anxiety", the construct was considered to be one-dimensional and was measured by scales such as the Test Anxiety Questionnaire, Mandler \& Sarason, 1952). Subsequently, field research has demonstrated that there are at least two dimensions present in measuring test anxiety. Liebert and Morris (1967) argued that "worry" and "emotionality" are present in measuring test anxiety and that they are two different dimensions. The Worry dimension refers to mind-distracting thoughts, self- 
disapproving rumination, and other types of distractors of the thinking process associated with evaluation. Vasey, Crnic and Carter (1994) refer to the cognitive characteristic of anxiety as "an anticipatory cognitive process involving repetitive thoughts associated with possible threatening outcomes and their potential consequences" (p.530). The Emotionality dimension refers to the body responses that are associated with anxiety (increased heart rate, headaches, sweating, etc.) (Cassady, 2004a). Test Anxiety Scale (Sarason, 1978), and Test Anxiety Inventory (Spielberger et al., 1980) are two of the most popular tools that have been developed in close connection with these two dimensions of the test anxiety. While the studies confirmed the presence of the two dimensions, repetitively, unsolved psychometric problems persisted, such as the strong overlap between the two factors (Ware, Gallasi, \& Dew, 1990; Ferrando, Varea, \& Lorenzo, 1999). The cognitive component of test anxiety (worry) is the most commonly found factor associated with the decline in performance (Hembree, 1988). In addition to the evidence available through traditional correlation studies and meta-analyzes, it has been confirmed that cognitive test anxiety has the closest connection to performance. While the analyzes did not support the existence of significant influence of the emotional component, the link between worry and academic results proved to be significant in adolescents (Williams, 1991) and students (Bandalos, Yates, \& Thorndike- Christ, 1995).

However, there have been studies that have shown that test anxiety can also have a positive influence on performance. More specifically, it has been shown that anxiety affects performance in complex or difficult tasks that require cognitive resources, such as the difficult items of an intelligence test, while performance in mild, less complex and repetitive tasks is not affected, on the contrary (Hembree, 1988; Zeidner, 1998, 2007). Also, although anxiety is likely to have negative effects among many students, it may facilitate general performance in those who are more flexible and can use in a productive way its motivational energy (Pekrun \& Linnenbrink-Garcia, 2012).

\section{Emotional regulation in academic context}

Emotional regulation can be defined as a set of processes through which people seek to redirect the spontaneous flow of their emotions. During emotional regulation, people can 
intensify, maintain or reduce positive and negative emotions. Therefore, emotional regulation often involves changes in the emotional response. These changes can occur in the type of emotions that people have when they live, or in the way of experimentation and expression of emotions (Gross, 1999). Emotions have several components, consisting of behavioral and physiological responses that are accompanied by specific thoughts and feelings (Parkinson et al., 1996; Mauss et al., 2005), and because emotional regulation acts on people's emotions, it results that the effects of this process can be observed on all emotional responses, including behavioral, physiological, or thoughts and feelings (Koole, 2009).

Regarding the evaluation in the academic context, some students can consciously engage in trying to reduce unpleasant feelings during evaluations, but there is a possibility that the adoption of specific strategies may not necessarily produce the results they want (John \& Gross, 2007). Otherwise conceptualized, emotional regulation is one of the forms of affect regulation that involves attempts to modify some aspects of the interaction between the individual and the environment, coded by the individual in a certain manner (Gross, Richards, \& John, 2006).

In terms of research in the academic field on emotions and emotional regulation, the subject that attracted attention was that of anxiety manifested in the evaluative context (Pekrun et al., 2002a, Schutz \& Pekrun, 2007) or "test anxiety" and the way that students manage their anxiety during the examination process (Kondo, 1997).

Although empirical evidence is limited, there are still some premises in the literature that emotions and emotional regulation are associated with academic performance, indirectly through motivation and involvement. Emotions have a substantial effect on motivation, cognition and action of the students by orienting mental and physiological energy in accomplishing the tasks and also by directing attention to the positive or negative aspects related to themselves and their tasks (Pekrun et al., 2002a). Indeed, there are results of studies that indicate that emotions are associated with academic motivation (Mega, Ronconi, \& De Beni, 2014, Pekrun et al., 2002a), and that dispositional affect is associated with the degree of involvement of students in the tasks (Linnenbrink-Garcia, Rogat, \& Koskey, 2011). 
Gross and Munoz (1995) present five different families of emotional regulation strategies: situation selection, situation modification, attentional deployment, cognitive change, and response modulation. The selection of the situation refers to the fact that individuals avoid certain situations, persons or contexts to try to reduce unpleasant emotions or, on the contrary, look for certain situations, people or contexts as a way to enhance the pleasant emotions. Changing the situation involves efforts to change a situation so that the emotional impact is different. In the evaluative context, most students do not have the opportunity to approach this strategy. Evaluations are mostly set by teachers or by regulations regarding their format, time, or other organizational details. In attentional deployment, individuals try to focus on the more or less important aspects of the context in trying to regulate their emotions. The goal is either to distract attention or to focus on the elements of the situation. Davis, Schutz, and DeCuir (1999) found that students with lower levels of test anxiety used focusing strategies by focusing on easy tasks in a test at an initial stage, then returning to the most difficult ones. Cognitive change refers to the attempt to build a more positive sense by reevaluating the experience. Each of these four types of regulatory strategies could be considered as focus-based strategies, because when they are used, the intention is to try to modify some elements of the context or the judgments that cause the emotion. Instead, during modulation of the response, individuals act directly on the experimented emotion (such as trying to suppress it).

Regarding the evaluative context, Schutz and collaborators (Schutz et al., 2008) identified three different dimensions of coping that students use in managing the difficulties encountered during evaluations: task-focused processes, regaining task focus, and emotionfocused processes. In terms of the first of these dimensions, that of task-focused processes, its key element is that the students wonder what strategies they need to use when solving the task. For example, during an assessment, students' thoughts might be about how they will manage their time in solving tasks, or how to formulate the answer to a question using the answers of other questions already solved. These thoughts help students keep their focus on the test and not on some possible disrupters. This strategy largely reflects what Gross (2002) highlights by attentional deployment, namely that students focus on those elements of the assessment they can control, such as reading instructions in solving, 
identifying key ideas in questions, eliminating responses, and so on. This change in the way of managing attention favors students to eliminate the elements that confuse them and focus on what they understand, supporting not only the regulation of emotions but also how to organize and solve the concrete tasks of the evaluation (Davis, DiStefano \& Schutz, 2008).

The second dimension is about emotion-focused processes, and it refers to the fact that the attention of the students is reoriented from the task to themselves and the emotions related to the task. More specifically, this involves a disengagement from the task received and a reorientation of the focus on feelings and thoughts about their performance related to the work task and the possible causes of that performance. These emotion-focused thoughts tend to distract the attention from the assessment task and may decrease performance and results (Davis, DiStefano \& Schutz, 2008). This strategy can be similar to what Gross (2002) calls attentional deployment (because students can focus on thinking about how the teacher will note that task) or cognitive change (by student taking responsibility for the insufficient training for the evaluation).

Davis and collaborators (2008) argue that there is still a third dimension involved in the management of the difficulties during the evaluations, called the processes of regaining the focus on task, which refers to the students' attempts to "return" to the task by reducing the tension experienced or by bringing the evaluative task to the foreground. Thus, these processes tend not to be focused on either task or emotion. Realizing a parallel with the strategies proposed by Gross (2002), the two previously mentioned seem to target different families, of which the reduction of tension reflecting students' attempts to modulate the response (e.g. suppressing unpleasant feelings) and re-appraising the importance of the test, reflecting the students' cognitive change (for example giving the assessment another importance in achieving its own goals).

\section{Method}

\subsection{Participants (Sample)}

The selected group of subjects consisted of 541 teenagers ( 357 girls and 184 boys), 9th-12th grade students, aged between 15 and 19 years $(M=16.71, S D=1.17)$ who 
participated in various national Olympiads. Distribution by gender variable was as follows: $66 \%$ girls and $34 \%$ boys. In the study were selected students participating in various competitions targeting the following subjects: Romanian Literature, English, French, Italian, Portuguese, Spanish, Reading as Life Skills, Socio-Human Sciences, Religion, Geography, History, Mathematics, Biology, Informatics, Physics, and Chemistry. They were selected from the public lists on the official Olympics websites and contacted online to complete a set of 3 questionnaires.

\subsection{Measures}

Test Anxiety Invetory

Developed by Spielberger (1980), the Test Anxiety Inventory (TAI) is according to Chapell et al. (2005), the most important and often used tool in measuring test anxiety among high school students and higher educationstudents. The Test Anxiety Inventory translated and adapted for an educational competition context (Olympiads and Interdisciplinary Competitions) (Holic, 2018a) consisting of 20 items, grouped into three distinct dimensions (Worry, Emotionality and Total Anxiety).Test Anxiety Inventory is a scale of responses that is measured by the 4 steps (Likert scale), the respondents options for choosing the answer are as follows: "1" - "Almost never", "2" - "Sometimes", “3” - “Often”, and "4" -"Almost always".

The TAI is a self-reporting questionnaire consisting of 20 items, which are distributed on the three scales as follows Test Anxiety-Total (TAI-T) with items 1, 12, 13 and 19; Test Anxiety-Worry (TAI-W) containing items 3, 4, 5, 6, 7, 14, 17, 20; and the Test AnxietyEmotionality (TAI-E) Scale consisting of items 2, 8, 9, 10, 11, 15, 16, 18. Thus, TAI-W contains 8 items, TAI-E 8 items, and 4 items make up the TAI-T scale.

The internal consistency for each of the three subscales in the case of the translated and adapted version (Holic, 2018a) for the competitive contexts was: .89 for the Test Anxiety-Total (TAI-T); .73 for Test Anxiety-Worry (TAI-W); and .86 for the Test AnxietyEmotionality (TAI-E), and .86 for the entire questionnaire.

Emotion Regulation Questionnaire 
Emotion Regulation Questionnaire (ERQ, Gross \& John, 2003) contains 10 items distributed on two scales that measure the usual use of cognitive reappraisal and suppression. The results presented below indicate that ERQ is a valid tool to measure individual differences in cognitive reappraisal and suppression. In recent years, this tool has been translated and adapted into many languages, all of which have acceptable internal consistency indicators for both scales.

The answers to the questionnaire items relates to the level of agreement with the statements presented in the items and are measured by the seven-points rating scale (Likert), where the respondents options for selecting the answer are as follows:1 - "strong disagreement" and 7 -"strong agreement" with the statement. For calculating the final score for each scale, the arithmetic mean of the scores of the items corresponding to the scale is calculated.

Alpha Cronbach's internal consistency coefficients of scales translated into the Romanian language (Heilman, 2011) were .74 for cognitive reappraisal, and .72 for suppression.

Emotion Regulation during Test-Taking

The translated and adapted version of Emotion Regulation during Test-Taking (ERT) for a competitive context (Holic, 2018b), after the original one (Emotion Regulation during Test-Taking, Schutz et al., 2008). Emotional Regulation during Test-Taking Scale (Schutz et al., 2008) consists of four dimensions: 1) Task-focusing Processes associated with the evaluation process; 2) Emotion-focusing Processes associated with evaluation process; 3) Regaining Task-focusing Processes associated with evaluation; and 4) Cognitive-appraising Processes associated with the transaction between the person-directed goal and the environment.

Each dimension comprises one or more subscales as follows:

- The Task-focused Processes dimension includes the Task-focused Strategy Use subscale

- The Emotion-focusing Processes dimension includes Wishful Thinking subscale and Self-blame subscale 
- The Regaining Task-focusing Processes dimension includes Importance Reappraisal subscale and Tension Reduction subscale

- The Cognitive-appraising Processes dimension includes Goal Congruence subscale, Agency subscale and Testing Problem-Efficacy subscale

The answer to the questionnaire items refers to the frequency with which respondents use that type of strategy, and is a 5-point Likert response format with the following anchor labels 1 = "Almost Never", 3= "Sometimes", and 5 ="Almost Always".

Alpha Cronbach's internal consistency coefficients of scales translated for the Romanian version were: .56 for Task-focused Processes dimension; .72 for Wishful Thinking Subscale and .86 for Self-blame Subscale; .64 for Importance Reappraisal Subscale and .81 for Tension Reduction Subscale; .65 for Goal Congruence Subscale, .82 for Agency Subscale, and .82 for Testing Problem-Efficacy Subscale. The internal consistency for the entire Emotional Regulation during the Test-Taking Scale was an acceptable one (Alpha Cronbach $=.706)$ (Holic. $2018 b)$.

\subsection{Results}

Correlation analysis

To test the moderation relationship, the correlations between the scales of test anxiety, emotional regulation strategies (Gross\&John, 1998; Schutz et al., 2008) and performance were initially analyzed.

Table 1 shows correlations between test anxiety, cognitive test anxiety, emotionality test anxiety, cognitive reappraisal, suppression, task-focused strategies, emotion-focused strategies, regaining task-focusing strategies, cognitive-appraising strategies, and performance. 
Table1.Correlations between test anxiety, cognitive test anxiety, emotionality test anxiety, cognitive reappraisal, suppression, task-focused strategies, emotion-focused strategies, regaining task-focusing strategies, cognitive-appraising strategies, and performance

\begin{tabular}{|c|c|c|c|c|c|c|c|c|c|c|c|}
\hline & (1) & (2) & (3) & (4) & (5) & (6) & (7) & (8) & (9) & (10) & (11) \\
\hline (1)test anxiety & - & & & & & & & & & & \\
\hline (2)cognitive test anxiety & $.885^{* *}$ & - & & & & & & & & & \\
\hline (3)emotionality test anxiety & $.923^{* *}$ & $.678^{* *}$ & - & & & & & & & & \\
\hline (4)cognitive reappraisal & -.051 & -.014 & $-.096^{*}$ & - & & & & & & & \\
\hline (5)suppression & $.105^{*}$ & $.173^{* *}$ & .046 & .026 & - & & & & & & \\
\hline (6)task-focused strategies & $.140^{* *}$ & $.157^{* *}$ & $.097^{*}$ & $.241^{* *}$ & -.012 & - & & & & & \\
\hline (7)emotion-focused strategies & $.614^{* *}$ & $.627^{* *}$ & $.484^{* *}$ & .020 & $.093^{*}$ & $.241^{* *}$ & - & & & & \\
\hline $\begin{array}{c}\text { (8)regaining task-focusing } \\
\text { strategies }\end{array}$ & $.089 *$ & $.092^{*}$ & .045 & $.312^{* *}$ & -.042 & $.187^{* *}$ & $.155^{* *}$ & - & & & \\
\hline (9)cognitive-appraising strategies & $-.475^{* *}$ & $-.441^{* *}$ & $-.418^{* *}$ & $.165^{* *}$ & -.080 & -.011 & $-.415^{* *}$ & -.011 & - & & \\
\hline $\begin{array}{l}\text { (10)general emotion regulation } \\
\text { strategies (Schutz et al., 2008) }\end{array}$ & $.237^{* *}$ & $.270^{* *}$ & $.147^{* *}$ & $.317^{* *}$ & -.004 & $.458^{* *}$ & $.595^{* *}$ & $.662^{* *}$ & $.263^{* *}$ & - & \\
\hline (11)performance & .067 & $.105^{*}$ & .024 & .071 & $-.085^{*}$ & $.097^{*}$ & $.114^{* *}$ & .061 & $-.175^{* *}$ & .033 & - \\
\hline
\end{tabular}


Testing the moderation relationship

In the next step we will investigate the relationship between test anxiety, and its cognitive and emotionality components, emotional regulation strategies and performance through a moderation relationship where emotional regulation strategies are considered as a moderator of the relationship between test anxiety and performance. Because we have used two different conceptualization of emotion regulation strategies (Gross \& John, 1998; Schutz et al., 2008), we will test this relationship with each of them. Thus, in the first step of each hierarchical regression, test anxiety, cognitive test anxiety and emotional test anxiety were introduced, then each of the emotional regulation strategies in the second step, and in the third step was included the interaction between the two variables.

The tables contain standardized beta indices are to be found in the Annexes of this paper.

\section{Discussion}

The objective of our study was to investigate the relationship between test anxiety and the emotional regulation strategies used. We also wanted to identify the extent to which the relationship between test anxiety and performance in national Olympics is moderated by the emotional regulation strategies used. Thus, we assumed that some of the emotional regulation strategies used, such as cognitive reappraisal (Gross \& John, 1998), task-focused strategies, emotion-focused strategies, regaining task-focusing strategies and cognitiveappraising strategies (Schutz et al., 2008) will be more effective in managing the effect of test anxiety (and its components) on performance. Because we have used two different models of emotional regulation strategies, it resulted several models of moderation.

In a first step, we have used the conceptualization released by Gross and John (1998), which presents two of the most studied strategies of emotional regulation, the cognitive reappraisal and expressive suppression. Cognitive reappraisal is defined as the attempt to reinterpret a situation that generate emotions in a way that can change its meaning and emotional impact (Lazarus \& Alfert, 1964, Gross \& John, 2003). Expressive suppression is defined as the attempt to hide, inhibit, or reduce the expressive emotional behavior (Gross \& Levenson, 1993; Gross \& John, 2003). Thus, we developed a model for test anxiety and each of its components and the two types of strategies mentioned above and the performance achieved. Analyzing the results, it was noted that none of the emotional 
regulation strategies used by the Olympics participants (cognitive reappraisal and suppression) was a moderator in the relationship between anxiety manifested in a competitive context and performance.

In a second step, we used the model developed by Schutz and collaborators (2008) which distinguishes between four different categories of coping that students use in managing the difficulties encountered during evaluations: task-focused processes/strategies, regaining task-focusing processes/strategies, emotion-focused processes/strategies, and cognitiveappraising processes/strategies. Task-focused strategies are referring at the student's attempt to acquire and maintain the focus on task. In other words, what the student is thinking at the that moment refers to the activities by which he / she can acquire and maintain his / her focus on the evaluation and tasks that he / she has to accomplish during the assessment time. For example, during the evaluation process, students who use the taskfocused strategies, such as "time management" or "identifying the main idea within the exercise / activity", are more likely to remain focused during the evaluation. Ideally, these strategies are useful in gaining and maintaining focus on task. The second dimension of emotional regulation involves emotion-focused strategies / processes associated with evaluation. These involve a focus on the self and the emotions associated with work tasks. It may refer to a disconnection from the task and a focus on emotions (pleasant or unpleasant) and on thoughts about how the student is handling the work task and the potential causes of why things are going in that way. Within these processes, two key emotion-focused strategies / processes have been identified: Wishful Thinking, which involves thoughts about whether the problem simply disappears or the hope that the teacher / evaluator will not take into account the results obtained; and Self-blame, which involves the students' criticism towards their own person about how they are doing during the evaluation or about how they trained for the evaluation (Schutz et al., 2004, 2008). The third dimension of emotional regulation associated with evaluation involves attempts to regain focus on the task (Schutz et al., 2004, 2008). For example, students' attempts to reduce their tension during assessment through the breathing rate or by giving themselves a one-minute break, which may prevent or stop irrelevant thoughts from the work task received. Therefore, this can help students regain focus on the work they have to deal with. The potential usefulness of trying to reduce tension is to increase the chances of redirecting attention from oneself and 
the feelings they have about how they do during the assessment, to the concrete fulfillment of the task. In addition, reappraising the importance of evaluation, involving attempts to keep its significance or highlighting positive aspects within it, are also activities that can stop the student's irrelevant thoughts and therefore facilitate the reorientation of the attention needed to accomplish the tasks received.Such an example may be to keep in perspective the importance of evaluation in relation to other aspects of the student's life, which can redirect the self-irrelevant thinking towards self-focusing on the task (Schutz et al., 2004, 2008).

Cognitive-appraising strategies are the fourth dimension and refer to the appraisals that students make during the evaluation process. Schutz (Schutz et al., 2004, 2008) indicates that there are four key types of appraising that are associated with the type of emotions that emerged during the academic assessment. The first type refers to the importance or relevance of the assessment. For example, if a student appreciates the assessment as being not too relevant, an emotional experience is unlikely to occur. In other words, in order for emotions to emerge, the transaction between person and environment needs to be regarded as relevant in terms of its objective or importance. A second type of appraisal refers to the congruence of the perceived objective. A potential question might be the following - "What happens during the evaluation helps me to reach my goals?" If the answer to this question is "No", the emotions of the incongruent objective, such as anger or anxiety, are most likely to occur. If the answer to this question is "Yes", the emotions of the congruent objective, such as joy or pride, are more likely to occur. A third type of appraisal refers to agency, or student's appreciation about who controls or who has caused what happens in the transaction. If students appreciate the assessment as relevant to their objective, but they do not perform properly and consider it to be someone else's fault, this will most likely cause anger. And the fourth type of appraisal refers to the efficacy in solving problems during the evaluation or the potential in managing any issue that may arise during the evaluation. Thus, a model was developed for test anxiety (and each of its components), the four types of emotional regulation strategies and the performance achieved on the competitions. No statistically significant results have been obtained in this case, so we can say that none of the four strategies can be considered as a moderator variable in the case of the relationship between test anxiety and performance. However, some relationships between the variables analyzed were identified. For example, emotionality test anxiety has shown a negative relationship 
with cognitive reappraisal, meaning that participants who experience a high level of emotionality test anxiety during Olympics are using less cognitive reappraisal as a strategy to regulate emotion. In the case of cognitive test anxiety, a positive relationship has been identified with suppression, meaning that participants who have to some extent intrusive thoughts during competition use suppression to a high level. The same aspect was also identified in the case of general test anxiety, which showed a positive relationship with suppression. In the case of task-focused strategies, they have shown positive relationships with test anxiety and with each of its components (cognitive and emotionality). Thus, participants exhibiting a high level of test anxiety, or just one of its forms - cognitive or emotionality - use to a large extent strategies that are focusing on tasks. The same remarks can be made about emotion-focused strategies, which also showed positive relationships with test anxiety and its components. Also, participants who use the regaining task-focusing strategies to a high degree are those who experience high levels of general test anxiety and cognitive test anxiety. What can be noticed is that when levels of test anxiety, cognitive test anxiety, and emotionality test anxiety are high, participants use less the cognitive-appraising strategies. In terms of performance, it has a positive relationship with cognitive test anxiety, task-focused strategies and emotion-focused strategies, and a negative relationship with suppression and cognitive-appraising strategies.

What can be remarked in this study is that the results show that, at least in the case of educational competitions involving adolescents with high intellectual abilities, the anxiety experienced during the evaluation has a positive influence on performance. This was also shown in other studies where the results were similar. Authors such as Pekrun and Linnenbrink-Garcia (2012) have argued that test anxiety can have a positive effect on performance when students are more flexible and can productively use the motivational energy provided by anxiety. Also, Hembree (1988) and Zeidner (1998; 2007) showed that the performance in repetitive tasks is not affected by anxiety on the contrary, it is improved. Thus, we can say that the Olympians through the training necessary for the competitions they are participating in are already familiar with the type of work tasks required.

The results also show that there is a positive relationship between test anxiety (and its two components, cognitive and emotionality) and the types of emotional regulation strategies used by the Olympics participants. Test anxiety (and its components) positively 
correlates with all emotional regulation strategies, less with cognitive reappraisal. Thus, we can state that adolescents participating in educational competitions who experience a high level of test anxiety (cognitive and emotionality) use to a great extent emotional regulation strategies such as suppression, task-focused strategies, emotion-focused strategies, regaining task-focusing strategies and cognitive-appraising strategies.

What is noteworthy and important to know by teachers and trainers of the adolescents that participate in national education competitions is that task-focused strategies and emotion-focused strategies have a positive influence on performance and cognitiveappraising strategies and suppression have a negative influence. We consider this to be an important thing for educational practice because teachers and trainers can take these aspects into account so that they can conceive activities that will form and develop strategies for teenagers whose influence is a positive one on performance and discourage the use of those strategies that proved to be ineffective.

Even if the results do not support the fact that emotional regulation strategies play the role of moderator in the relation between test anxiety and performance, yet these links identified between the variables analyzed can be a contribution to the educational practice, both for students participating in various educational competitions as well as in the case of day-to-day school performance.

\section{References}

Akca, F. (2011). The relationship between test anxiety and learned helplessness. Social Behaviour and Personality, 39(1),101-112.

Bandalos, D. L., Yates, K., \& Thorndike-Christ, R. (1995). The effects of math-self-concept, perceived self-efficacy, and attributions for success and failure on test anxiety. Journal of Educational Psychology, 87(4), 611624.

Bedell, J. Marlowe, H (1995). An evaluation of test anxiety scales: Convergent, discriminant, and predictive validity. In: Spielberger, C. and Vagg, P. (Eds.), Test Anxiety: Theory, assessment, and treatment, pp. 3545. Taylor \& Francis, Washington, DC.

Cassady, J.C. (2004a). Cognitive test anxiety and academic performance. Contemporary Educational Psychology 27, 270-295.

Chapell, M. S., Blanding, Z. B., Silverstein, M. E., Takahashi, M., Newman, B., Gubi, A., \&McCann, N. (2005). Test anxiety and academic performance in undergraduate and graduate students. Journal of Educational Psychology, 97(2),268-274.

Cohen, M., Ben-Zur, H., \& Rosenfeld, M. J. (2008). Sense of coherence, coping strategies, and test anxiety as predictors of test performance among college students. International Journal of Stress Management, 15(3),289-303. 
Davis, H. A., DiStefano, C., \& Schutz, P. A. (2008). Identifying patterns of appraising tests in first-year college students: Implications for anxiety and emotion regulation during test taking. Journal of Educational Psychology, 100(4), 942-960.

Davis, H. A., Schutz, P. A., \& DeCuir, J. T. (1999). "They can't tell me I'm stupid”: Undergraduate students coping with test anxiety. Paper presented at the annual meeting of the American Psychological Association, Boston, MA.

Ergene, T. (2003). Effective interventions on test anxiety reduction. A meta-analysis. School Psychology International, 24(3),313-328.

Ferrando, P.J., Varea, M.D., \& Lorenzo, U. (1999). A psychometric study of the Test Anxiety Scale for Children in a Spanish sample. Personality and Individual Differences, 16, 26-33.

Gross, J. J. (1999). Emotion regulation: Past, present, future. Cognition and Emotion, 13, 551-573.

Gross, J. J. (2002). Emotion regulation: Affective, cognitive, and social consequences. Psychophysiology, 39, 281291.

Gross, J. J., \& John, O. P. (1998). Mapping the domain of emotional expressivity: Multi-method evidence for a hierarchical model. Journal of Personality and Social Psychology, 74, 170-191.

Gross J. J. \& John O. P. (2003). Individual differences in two emotion regulation processes: implications for affect, relationships and well-being. Journal of Personality and Social Psychology, 85, 348-362.

Gross J. J. \& Levenson R. W. (1993). Emotional suppression: physiology, self-report and expressive behavior. Journal of Personality and Social Psychology,64, 970-986

Gross, J. J. \& Munoz, R. F. (1995). Emotion regulation and mental health. Clinical Psychology: Science and Practice, 2, 151-164.

Gross, J. J., Richards, J. M., \& John, O. P. (2006). Emotion regulation in everyday life. Snyder, Douglas K. (Ed); Simpson, Jeffry (Ed); Hughes, Jan N. (Ed). In Emotion regulation in couples and families: Pathways to dysfunction and health , (pp. 13-35). Washington, DC, US: American Psychological Association, xiv, 332 pp.

Heilman, R. M. (2011). Individual differences in emotion and decision (Diferențe individuale în emoție și decizie) (Public summary of the doctoral dissertation, consulted online).

Hembree, R. (1988). Correlates, causes, effects, and treatment of test anxiety. Review of Educational Research, $58,47-77$.

Holic, R. I. (2008a). The psychometric properties of the Romanian version of Test Anxiety Inventory adapted to a competitive academic context. (Article accepted for the proceedings of The Fifth International Conference on Adult Education. Education for values - continuity and context, April 2018).

Holic, R.I. (2018b). Validation of the Romanian version of Emotional Regulation during Test-Taking Scale adapted to the context of educational competitions (Article accepted in Journal of Innovation in Psychology, Education and Didactics, vol. 22(1)).

John, O. P., \& Gross, J. J. (2007). Individual differences in emotion regulation. In J. J. Gross (Ed.), Handbook of emotion regulation (pp. 351-372). New York: Guildford Press.

King, N.J., Ollendick, T. H., \& Prins, P. J. M. (2000). Test-anxious children and adolescents: psychopathology, cognition, and psychophysiological reactivity. Behaviour Change, 17, 134-142.

Kondo, D.S. (1997). Strategies for coping with test anxiety. Anxiety, Stress, and coping, 10, 203-15.

Koole, S. L.(2009). The psychology of emotion regulation: An integrative review. Cognition \& Emotion, 23(1),4 41.

Lazarus R. S. \& Alfert, E. (1964). Short-circuiting of threat by experimentally altering cognitive appraisal. The Journal of Abnormal and Social Psychology, 69, 195-205

Liebert, R. M., \& Morris, L. W. (1967). Cognitive and emotional components of test anxiety: A distinction and some initial data. Psychological Reports, 20, 975-978.

Linnenbrink-Garcia, L., Rogat, T. K., \& Koskey, K. L. K. (2011). Affect and engagement during small group instruction. Contemporary Educational Psychology, 36, 13-24. 
Mandler, G., \& Sarason, S. B. (1952). A study of anxiety and learning. Journal of Abnormal and Social Psychology, 47, 166-173.

Mauss, I. B., Levenson, R. W., McCarter, L., Wilhelm, F., \& Gross, J. J. (2005). The tie that binds? Coherence among emotion experience, behavior, and physiology. Emotion, 5, 175-190.

Mega, C., Ronconi, L., \& De Beni, R. (2014). What makes a good student? How emotions, selfregulated learning, and motivation contribute to academic achievement. Journal of Educational Psychology, 106, 121-131.

Methia, R.A. (2004). Help your child overcome test anxiety and achieve higher test scores. College Station, TX: VBW.

Parkinson , B., Totterdell, P., Briner, R .B., \& Reynolds, S. (1996). Changing moods: The psychology of mood and mood regulation. Harlow, UK : Longman.

Pekrun, R., Goetz, T., Frenzel, A. C., Barchfeld, P., \& Perry, R. P. (2011). Measuring emotions in students' learning and performance: The Achievement Emotions Questionnaire (AEQ). Contemporary Educational Psychology, 36(1), 36-48.

Pekrun, R., Goetz, T., Titz, W., \& Perry, R. (2002a). Academic emotions in students' self-regulated learning and achievement: A program of qualitative and quantitative research. Educational psychologist, 37(2), 91105.

Pekrun, R. \& Linnenbrink-Garcia, L. (2012). Academic emotions and student engagement. In S.L. Christenson et al. (eds.), Handbook of Research on Student Engagement.

Sarason, I. G. (1978). The test anxiety scale: concept and research. In C. D. Spielberger \& I. G. Sarason (Eds.), Stress and anxiety (Vol. 5). Washington, DC: Hemisphere Publishing Corp.

Sarason, I. G. (1980). Introduction to the study of test anxiety. In I. G. Sarason (Ed.), Test anxiety: Theory, research and applications (pp. 3-14). Hillsdale, NJ: Erlbaum.

Schutz, P. A., Benson, J., \& Decuir-Gunby, J. T. (2008). Approach/Avoidance motives, test emotions, and emotional regulation related to testing. Anxiety, Stress, and Coping, 21(3),263-281.

Schutz, P. A., DiStefano, C., Benson, J., \& Davis, H. A. (2004). The Emotional Regulation During Test Taking Scale. Anxiety, Stress, and Coping, 17, 253-259.

Schutz, P.A., \& Pekrun, R. (Eds.). (2007). Emotion in education. San Diego, CA: Academic Press.

Shobe, E., Brewin, A., \& Carmack, S. (2005). A Simple Visualization Exercise for Reducing Test Anxiety and Improving Performance on Difficult Math Tests. Journal of Worry \& Affective Experience, 1(1),34-52.

Spielberger, C. D. \& Vagg, P. R. (1995). Test anxiety: A transactional process model. In C. D. Spielberger \& P. R. Vagg (Eds.), Test anxiety: Theory, assessment and treatment (pp. 3-14). Washington, DC: Taylor \& Francis.

Trentacosta, C. J., \& Izard, C. E. (2007). Kindergarten children's emotion competence as a predictor of their academic competence in first grade. Emotion, 7, 77-88.

Valiente, C., Swanson, J., Lemery-Chalfant, K., \& Berger, R. H. (2014). Children's effortful control and academic achievement: Do relational peer victimization and classroom participation operate as mediators? Journal of School Psychology, 52, 433- 445.

Vasey, M.W., Crnic, K.A. \& Carter, W.G. Cogn (1994). Worry in childhood: A developmental perspective. Cognitive Therapy and Research, 18(6), 529-549.

Ware, B. W., Galassi, J. P., \& Dew, K. M. H. (1990). The test anxiety inventory: A confirmatory factor analysis. Anxiety Research, 3, 205-212.

Williams, J. E. (1991). Modeling test anxiety,selfconcept and high schoolstudents' academic achievement. Journal of Research and Development in Education, 25, 51-57.

Zeidner, M. (1998). Test anxiety: The state of the art. New York: Plenum.

Zeidner, M. (2007). Test anxiety in educational contexts: Concepts, findings, and future directions. In P. A. Schutz \& R. Pekrun (Eds.), Emotion in education (pp. 165-184). San Diego, CA: Academic Press.

Zeidner, M. \& Matthews, G. (2011). Anxiety 101. New York: Springer Publishing Company, LLC. 
Annexes

Multiple hierarchical regression of relation between test anxiety, suppression and performance

\begin{tabular}{|c|c|c|c|c|}
\hline & \multicolumn{4}{|c|}{ Performance } \\
\hline & $\beta$ & $\mathrm{t}$ & $\Delta \mathrm{R}^{2}$ & $\Delta \mathrm{F}$ \\
\hline Step 1 & & & .003 & 2.45 \\
\hline Test anxiety (general) & .067 & 1.57 & & \\
\hline Step 2 & & & .009 & $4.63^{*}$ \\
\hline Suppression & $-.093^{*}$ & -2.15 & & \\
\hline Step 3 & & & .008 & .06 \\
\hline Test anxiety * Suppression & .010 & .235 & & \\
\hline \multicolumn{5}{|c|}{$\begin{array}{c}\qquad{ }^{*} \mathrm{p}<.05 \\
\text { Multiple hierarchical regression of relation between cognitive test anxiety, suppression and performance }\end{array}$} \\
\hline & \multicolumn{4}{|c|}{ Performance } \\
\hline & $\beta$ & $\mathrm{t}$ & $\Delta \mathrm{R}^{2}$ & $\Delta \mathrm{F}$ \\
\hline Step 1 & & & .009 & $6.03^{*}$ \\
\hline Cognitive test anxiety & $.105^{*}$ & 2.46 & & \\
\hline Step 2 & & & .018 & $5.99^{*}$ \\
\hline Suppression & $-.106^{*}$ & -2.45 & & \\
\hline Step 3 & & & .017 & .019 \\
\hline Cognitive test anxiety $*$ Suppression & -.006 & -.136 & & \\
\hline \multicolumn{5}{|c|}{$\begin{array}{c}{ }^{*} \mathrm{p}<.05 \\
\text { Multiple hierarchical regression of relation between emotionality test anxiety, suppression and performance }\end{array}$} \\
\hline & \multicolumn{4}{|c|}{ Performance } \\
\hline & $\beta$ & $\mathrm{t}$ & $\Delta \mathrm{R}^{2}$ & $\Delta \mathrm{F}$ \\
\hline Step 1 & & & -.001 & .309 \\
\hline Emotionality test anxiety & .024 & .56 & & \\
\hline Step 2 & & & .004 & $3.99 *$ \\
\hline Suppression & $-.086^{*}$ & -2.00 & & \\
\hline Step 3 & & & .002 & .007 \\
\hline Emotionality test anxiety * Suppression & -.004 & -.084 & & \\
\hline
\end{tabular}

Multiple hierarchical regression of relation between test anxiety, cognitive reappraisal and performance

\begin{tabular}{ccccc}
\hline & \multicolumn{4}{c}{ Performance } \\
\cline { 2 - 5 } Step 1 & $\mathrm{t}$ & $\Delta \mathrm{R}^{2}$ & $\Delta \mathrm{F}$ \\
\hline $\begin{array}{c}\text { Step 2 } \\
\text { Test anxiety (general) }\end{array}$ & .067 & 1.57 & .003 & 2.45 \\
\hline $\begin{array}{c}\text { Stegnitive reappraisal } \\
\text { Step 3 }\end{array}$ & .075 & 1.75 & .075 & 1.75 \\
\hline $\begin{array}{c}\text { Cost anxiety* Cognitive reappraisal } \\
\text { Test }\end{array}$ & -.003 & -.063 & .005 & .004 \\
\hline
\end{tabular}

Multiple hierarchical regression of relation between cognitive test anxiety, cognitive reappraisal and performance

\begin{tabular}{ccccc}
\hline & \multicolumn{4}{c}{ Performance } \\
\cline { 2 - 5 } & $\mathrm{B}$ & $\mathrm{t}$ & $\Delta \mathrm{R}^{2}$ & $\Delta \mathrm{F}$ \\
\hline $\begin{array}{c}\text { Step 1 } \\
\text { Cognitive test anxiety }\end{array}$ & $.105^{*}$ & 2.46 & .009 & $6.03^{*}$ \\
\hline $\begin{array}{c}\text { Step 2 } \\
\text { Cognitive reappraisal }\end{array}$ & .073 & 1.71 & .013 & 2.91 \\
\hline $\begin{array}{c}\text { Step 3 } \\
\text { Cognitive test anxiety* Cognitive reappraisal }\end{array}$ & -.004 & -.101 & .011 & .010 \\
\hline
\end{tabular}


${ }^{*} \mathrm{p}<.05$

Multiple hierarchical regression of relation between emotionality test anxiety, cognitive reappraisal and performance

\begin{tabular}{|c|c|c|c|c|}
\hline & \multicolumn{4}{|c|}{ Performance } \\
\hline & $\beta$ & $\mathrm{t}$ & $\Delta \mathrm{R}^{2}$ & $\Delta \mathrm{F}$ \\
\hline Step 1 & & & -.001 & .309 \\
\hline Emotionality test anxiety & .024 & .56 & & \\
\hline Step 2 & & & .002 & 2.98 \\
\hline Cognitive reappraisal & .074 & 1.73 & & \\
\hline Step 3 & & & .001 & .000 \\
\hline Emotionality test anxiety* Cognitive reappraisal & .000 & -.006 & & \\
\hline \multicolumn{5}{|c|}{ Multiple hierarchical regression of relation between test anxiety, task-focused strategies and performance } \\
\hline & \multicolumn{4}{|c|}{ Performance } \\
\hline & $\beta$ & $\mathrm{t}$ & $\Delta \mathrm{R}^{2}$ & $\Delta \mathrm{F}$ \\
\hline Step 1 & & & .003 & 2.45 \\
\hline Test anxiety (general) & .067 & 1.57 & & \\
\hline Step 2 & & & .009 & $4.24^{*}$ \\
\hline Task-focused strategies & $.089 *$ & 2.06 & & \\
\hline Step 3 & & & .007 & .003 \\
\hline Test anxiety* Task-focused strategies & -.002 & -.051 & & \\
\hline
\end{tabular}

Multiple hierarchical regression of relation between cognitive test anxiety, task-focused strategies and performance

\begin{tabular}{|c|c|c|c|c|}
\hline & \multicolumn{4}{|c|}{ Performance } \\
\hline & ß & $\mathrm{t}$ & $\Delta \mathrm{R}^{2}$ & $\Delta \mathrm{F}$ \\
\hline Step 1 & & & .009 & $6.03^{*}$ \\
\hline Cognitive test anxiety & $.105^{*}$ & 2.46 & & \\
\hline Step 2 & & & .014 & 3.62 \\
\hline Task-focused strategies & .082 & 1.90 & & \\
\hline Step 3 & & & .012 & .141 \\
\hline Cognitive test anxiety* Task-focused strategies & -.016 & -.375 & & \\
\hline
\end{tabular}

${ }^{*} \mathrm{p}<.05$

Multiple hierarchical regression of relation between emotionality test anxiety, task-focused strategies and performance

\begin{tabular}{ccccc}
\hline & \multicolumn{4}{c}{ Performance } \\
\cline { 2 - 5 } & $\beta$ & $\mathrm{t}$ & $\Delta \mathrm{R}^{2}$ & $\Delta \mathrm{F}$ \\
\hline $\begin{array}{c}\text { Step 1 } \\
\text { Emotionality test anxiety }\end{array}$ & .024 & .556 & -.001 & .309 \\
Step 2 & & & .006 & $4.89^{*}$ \\
Task-focused strategies & $.095^{*}$ & 2.21 & & .085 \\
\hline $\begin{array}{c}\text { Step 3 } \\
\text { Emotionality test anxiety* Task-focused strategies }\end{array}$ & .013 & .292 & .004 & \\
\hline
\end{tabular}

${ }^{*} \mathrm{p}<.05$

Multiple hierarchical regression of relation between test anxiety, emotion-focused strategies and performance

\begin{tabular}{ccccc}
\hline & \multicolumn{4}{c}{ Performance } \\
\cline { 2 - 5 } Step 1 & $\beta$ & $\mathrm{t}$ & $\Delta \mathrm{R}^{2}$ & $\Delta \mathrm{F}$ \\
\hline $\begin{array}{c}\text { Test anxiety (general) } \\
\text { Step 2 }\end{array}$ & .067 & 1.57 & .003 & 2.45 \\
\hline $\begin{array}{c}\text { Enotion-focused strategies } \\
\text { Step 3 }\end{array}$ & $.117^{*}$ & 2.16 & .009 & $4.66^{*}$ \\
\hline & & & .008 & .220
\end{tabular}


Test anxiety* Emotion-focused strategies

0.021

$-.469$ ${ }^{*} \mathrm{p}<.05$

Multiple hierarchical regression of relation between cognitive test anxiety, emotion-focused strategies and performance

\begin{tabular}{ccccc}
\hline & \multicolumn{4}{c}{ Performance } \\
\cline { 2 - 5 } & $\beta$ & $\mathrm{t}$ & $\Delta \mathrm{R}^{2}$ & \multicolumn{1}{c}{$\Delta \mathrm{F}$} \\
\hline $\begin{array}{c}\text { Step 1 } \\
\text { Cognitive test anxiety }\end{array}$ & $.105^{*}$ & 2.46 & .009 & $6.03^{*}$ \\
\hline $\begin{array}{c}\text { Step 2 } \\
\text { Emotion-focused strategies }\end{array}$ & .080 & 1.45 & .011 & 2.11 \\
\hline $\begin{array}{c}\text { Step 3 } \\
\text { Cognitive test anxiety* Emotion-focused strategies }\end{array}$ & -.042 & -.932 & .011 & .869 \\
\hline
\end{tabular}

$$
{ }^{*} \mathrm{p}<.05
$$

Multiple hierarchical regression of relation between emotionality test anxiety, emotion-focused strategies and performance

\begin{tabular}{ccccc}
\hline & \multicolumn{4}{c}{ Performance } \\
\cline { 2 - 5 } & $\beta$ & $\mathrm{t}$ & $\Delta \mathrm{R}^{2}$ & $\Delta \mathrm{F}$ \\
\hline $\begin{array}{c}\text { Step 1 } \\
\text { Emotionality test anxiety }\end{array}$ & .024 & .556 & -.001 & .309 \\
$\quad \begin{array}{c}\text { Step 2 } \\
\text { Emotion-focused strategies }\end{array} \quad .134^{*}$ & 2.74 & .011 & $7.52^{*}$ \\
\hline $\begin{array}{c}\text { Step 3 } \\
\text { Emotionality test anxiety*Emotion-focused strategies }\end{array}$ & -.001 & -.018 & .009 & .000 \\
\hline
\end{tabular}

${ }^{*} \mathrm{p}<.01$

Multiple hierarchical regression of relation between test anxiety, regaining task-focusing strategies and performance

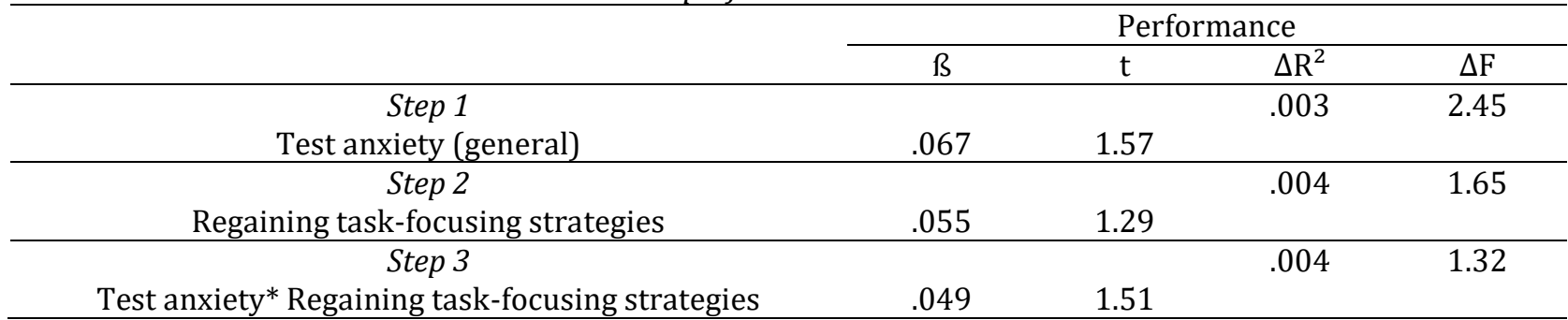

Multiple hierarchical regression of relation between cognitive test anxiety, regaining task-focusing strategies and performance

\begin{tabular}{ccccc}
\hline & \multicolumn{4}{c}{ Performance } \\
\cline { 2 - 5 } & $\beta$ & $\mathrm{t}$ & $\Delta \mathrm{R}^{2}$ & $\Delta \mathrm{F}$ \\
\hline $\begin{array}{c}\text { Step 1 } \\
\text { Cognitive test anxiety }\end{array}$ & .105 & 2.46 & .009 & $6.03^{*}$ \\
\hline $\begin{array}{c}\text { Step 2 } \\
\text { Regaining task-focusing strategies }\end{array}$ & .052 & 1.20 & .010 & 1.45 \\
\hline $\begin{array}{c}\text { Step 3 } \\
\text { Cognitive test anxiety* Regaining task-focusing strategies }\end{array}$ & .062 & 1.45 & .012 & 2.09 \\
\hline
\end{tabular}

$$
{ }^{*} \mathrm{p}<.05
$$

Multiple hierarchical regression of relation between emotionality test anxiety, regaining task-focusing strategies and performance

\begin{tabular}{lcccc} 
& \multicolumn{5}{c}{ Performance } \\
\cline { 2 - 5 } & $\mathrm{B}$ & $\mathrm{t}$ & $\Delta \mathrm{R}^{2}$ & $\Delta \mathrm{F}$ \\
Step 1 & & & -.001 & .309 \\
ality test anxiety & .024 & .556 & & \\
\hline
\end{tabular}




\begin{tabular}{|c|c|c|c|c|}
\hline $\begin{array}{c}\text { Step } 2 \\
\text { Regaining task-focusing strategies }\end{array}$ & .060 & 1.39 & .000 & 1.94 \\
\hline Step 3 & & & .000 & .860 \\
\hline $\begin{array}{l}\begin{array}{l}\text { Emotionality test anxiety* Regaining task-focusing } \\
\text { strategies }\end{array} \\
\end{array}$ & .040 & .927 & & \\
\hline \multicolumn{5}{|c|}{$\begin{array}{c}\text { Multiple hierarchical regression of relation between test anxiety, cognitive-appraising strategies and } \\
\text { performance }\end{array}$} \\
\hline & \multicolumn{4}{|c|}{ Performance } \\
\hline & $\beta$ & $\mathrm{t}$ & $\Delta \mathrm{R}^{2}$ & $\Delta \mathrm{F}$ \\
\hline Step 1 & & & .003 & 2.45 \\
\hline Test anxiety (general) & .056 & 1.57 & & \\
\hline Step 2 & & & .027 & $14.57^{*}$ \\
\hline Cognitive-appraising strategies & $-.184^{*}$ & -3.82 & & \\
\hline Step 3 & & & .027 & .676 \\
\hline Test anxiety* Cognitive-appraising strategies & .036 & .822 & & \\
\hline \multicolumn{5}{|c|}{$\begin{array}{c}{ }^{*} \mathrm{p}<.01 \\
\text { Multiple hierarchical regression of relation between cognitive test anxiety, cognitive-appraising strategies and } \\
\text { performance }\end{array}$} \\
\hline & \multicolumn{4}{|c|}{ Performance } \\
\hline & $\beta$ & $\mathrm{t}$ & $\Delta \mathrm{R}^{2}$ & $\Delta \mathrm{F}$ \\
\hline Step 1 & & & .009 & $6.03^{*}$ \\
\hline Cognitive test anxiety & $.105^{*}$ & 2.46 & & \\
\hline Step 2 & & & .028 & $11.33^{* *}$ \\
\hline Cognitive-appraising strategies & $-.159 * *$ & -3.37 & & \\
\hline Step 3 & & & .026 & .154 \\
\hline Cognitive test anxiety* Cognitive-appraising strategies & .017 & .393 & & \\
\hline \multicolumn{5}{|c|}{$\begin{array}{c}{ }^{*} \mathrm{p}<.05^{* *} \mathrm{p}<.01 \\
\text { Multiple hierarchical regression of relation between emotionality test anxiety, cognitive-appraising strategies } \\
\text { and performance }\end{array}$} \\
\hline & \multicolumn{4}{|c|}{ Performance } \\
\hline & $\beta$ & $\mathrm{t}$ & $\Delta \mathrm{R}^{2}$ & $\Delta \mathrm{F}$ \\
\hline Step 1 & & & -.001 & .309 \\
\hline Emotionality test anxiety & .024 & .556 & & \\
\hline Step 2 & & & .030 & $18.25^{*}$ \\
\hline Cognitive-appraising strategies & $-.199 *$ & -4.27 & & \\
\hline Step 3 & & & .030 & 1.04 \\
\hline Emotionality test anxiety* Cognitive-appraising strategies & .044 & 1.02 & & \\
\hline \multicolumn{5}{|c|}{$\begin{array}{c}{ }^{*} \mathrm{p}<.01 \\
\text { Multiple hierarchical regression of relation between test anxiety, emotion regulation strategies (Schutz et al., } \\
\text { 2008) and performance }\end{array}$} \\
\hline & \multicolumn{4}{|c|}{ Performance } \\
\hline & $ß$ & $\mathrm{t}$ & $\Delta \mathrm{R}^{2}$ & $\Delta \mathrm{F}$ \\
\hline $\begin{array}{c}\text { Step } 1 \\
\text { Test anxiety (general) }\end{array}$ & .067 & 1.57 & .003 & 2.45 \\
\hline Step 2 & & & .001 & .167 \\
\hline Emotion regulation strategies (general) & .018 & .409 & & \\
\hline Step 3 & & & .000 & .366 \\
\hline Test anxiety* Emotion regulation strategies & .026 & .605 & & \\
\hline \multicolumn{5}{|c|}{$\begin{array}{c}\text { Multiple hierarchical regression of relation between cognitive test anxiety, emotion regulation strategies (Schutz } \\
\text { et al., 2008) and performance }\end{array}$} \\
\hline & \multicolumn{4}{|c|}{ Performance } \\
\hline & $\beta$ & $\mathrm{t}$ & $\Delta \mathrm{R}^{2}$ & $\Delta \mathrm{F}$ \\
\hline $\begin{array}{c}\text { Step } 1 \\
\text { Cognitive test anxiety }\end{array}$ & $.105^{*}$ & 2.46 & .009 & $6.03^{*}$ \\
\hline
\end{tabular}


Journal of Educational Sciences, XIX • nr. 2(38) • 2018

\begin{tabular}{|c|c|c|c|c|}
\hline $\begin{array}{c}\text { Step } 2 \\
\text { Emotion regulation strategies (general) }\end{array}$ & .005 & .112 & .007 & .013 \\
\hline Step 3 & & & .006 & .003 \\
\hline $\begin{array}{l}\text { Cognitive test anxiety* Emotion regulation strategies } \\
\text { (general) }\end{array}$ & .002 & .057 & & \\
\hline \multicolumn{5}{|c|}{$\begin{array}{l}{ }^{*} \mathrm{p}<.05 \\
\text { Multiple hierarchical regression of relation between emotionality test anxiety, emotion regulation strategies } \\
\text { (Schutz et al., 2008) and performance }\end{array}$} \\
\hline & \multicolumn{4}{|c|}{ Performance } \\
\hline & $\beta$ & $\mathrm{t}$ & $\Delta \mathrm{R}^{2}$ & $\Delta \mathrm{F}$ \\
\hline Step 1 & & & -.001 & .309 \\
\hline Emotionality test anxiety & .024 & .556 & & \\
\hline Step 2 & & & -.002 & .480 \\
\hline Emotion regulation strategies (general) & .030 & .693 & & \\
\hline Step 3 & & & -.002 & 1.08 \\
\hline $\begin{array}{l}\begin{array}{l}\text { Emotionality test anxiety* Emotion regulation strategies } \\
\text { (general) }\end{array} \\
\end{array}$ & .045 & 1.04 & & \\
\hline
\end{tabular}

